\title{
Proceso de Paz: negociaciones multilaterales para un proceso sostenible de paz (vídeo-performance)
}

\author{
Peace Process: multilateral negotiations for a sustainable peace process \\ (video-performance)
}

\author{
Jesús Algovi González Villegas \\ Universidad de Sevilla (España) \\ jesusalgovi@gmail.com
}

\author{
Recibido 03/09/2020 Revisado 10/11/2020
}

Aceptado 17/11/2020 Publicado 30/11/2020

\section{Resumen:}

"Proceso de Paz" es una vídeo-performance, de la que soy autor, realizada en 2009, cuyo elemento fundamental es el propio cuerpo. Pero es un "body art" uniformado con un pasamontañas y las desnudas palomas del parque de María Luisa. Una pieza muy sencilla, pero a su vez efectiva, como metáfora (no exenta de sarcasmo), sobre la situación contemporánea de la política internacional. La paradoja de un símbolo militar o de poder (el uniforme militar y el anonimato del pasamontañas) que ejerce una sensación de miedo, ya sea por la utilización desde el terror o el ámbito de la autoridad militar o policial. Esta figura cuya imagen condensa una amenaza o violencia, alimentando y atrayendo paulatinamente a las palomas, símbolo tradicional e icono de la paz. Metáfora sobre la violencia ejercida por los estados con grandes eventos eufemísticos de paz, conceptos de guerra preventiva o una impostada libertad.

Sugerencias para citar este artículo,

Algovi González Villegas, Jesús (2020). Proceso de Paz: negociaciones multilaterales para un proceso sostenible de paz (vídeo-performance). Tercio Creciente (Monográfico extraordinario III), págs. 129-135, https://dx.doi.org/10.17561/rtc.extra3.5725

ALGOVI GONZÁLEZ VILLEGAS, JESÚS (2020) Proceso de Paz: negociaciones multilaterales para un proceso sostenible de paz (vídeo-performance). Tercio Creciente (Monográfico extraordinario III), noviembre 2020, pp. 129-135, https://dx.doi.org/10.17561/rtc.extra3.5725 


\begin{abstract}
:
"Process of Peace" is a video-performance, of which I am the author, made in 2009, whose fundamental element is the body art. But it is a "body art" uniformed with a balaclava and the naked doves of María Luisa's park. A very simple piece, but at the same time effective, as a metaphor (not without sarcasm), about the contemporary situation of international politics. The paradox of a military or power symbol (the military uniform and the anonymity of the balaclava) that exerts a feeling of fear, either due to the use of terror or the sphere of military or police authority. This figure whose image condenses a threat or violence, gradually feeding and attracting doves, a traditional symbol and icon of peace. Metaphor about the violence exerted by states with great euphemistic events of peace, concepts of preventive war or an imposed freedom.
\end{abstract}

Palabras Clave: Vídeo-performance, arte contemporáneo, body art, arte de acción, arte y política

Key words: Video-performance, current art, body art, action art, art and politic

Sugerencias para citar este artículo,

Algovi González Villegas, Jesús (2020). Proceso de Paz: negociaciones multilaterales para un proceso sostenible de paz (vídeo-performance). Tercio Creciente (Monográfico extraordinario III), págs. 129-135, https://dx.doi.org/10.17561/rtc.extra3.5725

ALGOVI GONZÁLEZ VILLEGAS, JESÚS (2020) Proceso de Paz: negociaciones multilaterales para un proceso sostenible de paz (vídeo-performance). Tercio Creciente (Monográfico extraordinario III), noviembre 2020, pp. 129-135, https://dx.doi.org/10.17561/rtc.extra3.5725 
ISSN: $2340-9096$

https://dx.doi.org/10.17561/rtc.extra3.5725

\section{El proyecto}

Es muy curioso que el inicio de esta obra sea el producto de un rechazo. Una lección de cómo no se debe de renunciar a una idea por el mero desprecio de un supuesto experto o juez en la materia. Detrás de esta breve performance pensada para vídeo (de 5 minutos de duración) hay una experiencia vital interesante que voy a desarrollar en este artículo. Artículo que es fruto, a su vez, del I Congreso Internacional Virtual de Artes CIVARTES 2020, Diálogos entre las artes plásticas y visuales y otros medios artísticos en tiempos de hibridación. Este congreso ha tenido la excepcionalidad (nada usual en el ámbito puramente académico) de permitir la participación en el mismo con una pura pieza de arte contemporáneo. Esto no es asunto baladí, ya que por desgracia llevamos demasiados años luchando para que en el ámbito académico universitario se entienda que los artistas plásticos trabajamos en la búsqueda de nuevas formas en el arte contemporáneo, dentro de la mal entendida y denostada "vanguardia artística", estamos investigando. Es decir, nuestras obras son fruto de la investigación más pura. Aquellos que a su vez estamos en el ámbito de la docencia universitaria, nos resistimos a que dentro de la misma se desprecie de la manera más futil nuestro trabajo de investigación y se nos remita a la pura redacción de artículos como éste. Por supuesto que es interesante y de gran valor para la investigación académica estos artículos y su posterior publicación en una revista indexada. Ineludible si queremos progresar en este mundo de méritos académicos y aportación de certificaciones que lo acrediten. Pero en el ámbito de las Bellas Artes y del arte contemporáneo, debemos contemplar el doble esfuerzo que debemos realizar tanto como artistas, investigadores y docentes. Es por tanto de agradecer que se generen fisuras y nuevos espolones académicos como está haciendo de manera ejemplar la Universidad de Jaén con estos claros ejemplos que nos permiten poner en valor la creación como investigación.

El sistema universitario debe entender que una pintura, una instalación, una performance o cualquier otra disciplina o soporte físico de la expresión plástica, al igual que una fórmula para un matemático, se debería equiparar, como paradigma de investigación al igual que una artículo de texto escrito convencional como es este caso que estáis leyendo en este momento. El arte es un lenguaje propio y como las matemáticas hay que tener el conocimiento suficiente para descifrar su grandeza o nimiedad. Para un físico e=mc2 es algo grandioso, genial e incomparable. Esto que parece de perogrullo, resulta un handicap inalcanzable e incomprensible (al parecer) para muchas instituciones, con respecto a la creación visual. Esperemos que esto cambie. 
Pues de vuelta al inicio y a la historia que rodea entre bambalinas esta vídeo-performance. Una joven artista e incipiente comisaria, de nombre es Rinat Izhak es el accidentado germen de esta pieza. Una artista de origen israelí que vive y trabaja en España desde 1999. Centrada en la creación artística en Sevilla en los últimos años, siendo la raíz en su proyecto La Plaza de las Palomas (desarrollado entre finales 2007-2010, incluido).

"Este trabajo se ha encargado de resumir la historia de las últimas ocho décadas de la ciudad, a través de los fragmentos fotográficos que han quedado vinculados al emblemático espacio de la Plaza de América, ubicada en el Parque María Luisa. En él se lee la ciudad y su historia a través de los recuerdos personales locales atados a este lugar, indisoluble a la identidad sevillana, que une a tanta gente como referente común."

El proyecto basaba (supuestamente) una de sus líneas estratégicas en la participación, incitando al impacto social y al pensamiento colectivo. Extrayendo del imaginario común la fuerte esencia de esta plaza, las personas comparten libremente sus recuerdos personales, principalmente familiares, mandando sus fotografías a la página web del proyecto. Estos sirven como la materia prima para mi creación: pintura, instalación, vídeo, teatro, fotografía, contando también con la colaboración de cuarenta artistas sevillanos.

El resultado fue una creación común con la que los participantes y visitantes se "sintieron fuertemente vinculados emocional y vitalmente". Tuvo lugar en el Museo de Artes y Costumbres Populares de Sevilla, del 14 de mayo al 5 de septiembre de 2010 y una intervención artística en dicha plaza, del 13 de mayo al 10 de junio de 2010.

Sus objetivos eran recuperar el valor del espacio público y promover la participación social a través del hecho artístico. Mostrar que eres una parte del universo que te rodea y no sólo quien lo contempla. Crear una página web con documentación y archivos de imágenes de la historia de esta plaza y sus visitantes.

En principio, y a pesar de ser esta nueva comisaria una auténtica desconocida, acepté la invitación que me hizo a través de conocidos artistas en los que tengo la suficiente confianza. Fue en 2009 cuando comunicó su intención y su invitación a que participase en su proyecto. 
Yo me inicié en el año 1985 en esto del arte contemporáneo. Como comprenderéis, y a tenor del año de su invitación, yo ya tenía una sólida carrera profesional internacional. Pero eso no me supuso (como de costumbre) un obstáculo para aceptar su propuesta de manera totalmente altruista, o sea, por puro amor al arte. Sin ningún tipo de presupuesto de producción, gastos de transporte, derechos de exhibición ni nada parecido a un serio comisariado respaldado institucionalmente. Pero como yo mismo he elaborado proyectos de este tipo, acepté su propuesta. Pensé participar con una breve propuesta de performance para vídeo. Conté con la colaboración de Ed Weber (Director de la Galería Weber-Lutgen de Sevilla) para la producción y realización del vídeo de la acción. Pero, es cierto, que (como es habitual en mi creación) no me conformé con la idea de la comisaria, de bucólica melancolía como lírica inocente de la memoria colectiva de mi ciudad, con cierto color folclórico y onírico que no me interesaba en absoluto. Como de costumbre, metí el dedo en la llaga de la ambigüedad política y en la militancia del creador con compromiso social. Realicé, en la Plaza de las Palomas (o de América) la performance, con un inequívoco y sarcástico sentido político. Esto, debió de molestar a esta joven comisaria judia-israelí y me censuró la pieza rechazándola.

Mi primera reacción fue la estupefacción. La segunda el enfado. La tercera fue fumarme un cigarro y dormir. No iba a darle la importancia que a ella le gustaría, a un proyecto insulso, con una publicidad gratuita. Si hacía pública mi protesta por dicha pura censura era darle por mi parte una importancia que no estaba dispuesto a regalarle. Opté por el silencio hasta este momento, más de una década y en este artículo.

La acción se desarrollaba en un lateral de la Plaza de América (más conocida como "De las Palomas") dentro del Parque de maría Luisa de Sevilla, en junio de 2009. Frente a un seto de ciprés, a modo de verde pared, aparecía (transición transparente) vestido de traje militar negro con pasamontañas negro. Armado de unos paquetes de cañamones (comida para las palomas que venden en el puesto ambulante en la misma plaza). Poco a poco iba dando estas semillas a las palomas, que se van paulatinamente acercando a mí hasta rodearme, posarse sobre mí y comer de mi mano. Tras un rato de "control" sobre ellas, en base al racionamiento y dominio de su alimento, desaparezco como llegué...con una transición hacia el vacío y el silencio absoluto. 
Su título "Proceso de Paz: negociaciones multilaterales para un proceso sostenible de paz", es bastante evidente. Sarcasmo absoluto sobre los ridículos y eufemísticos "procesos de paz", controlados por las naciones poderosas y por los intereses particulares de las grandes instituciones financieras, multinacionales y lobbys económicos. Como en el caso de la propia Israel y Palestina. O cualquier otro conflicto internacional. Es el interés económico (el "alpiste") el que finalmente se suele imponer frente a la razón o la justicia más elementales.

Esta pieza formó parte de la exposición "HIGH DENSITY" en la Galería Weber-Lutgen, en el mes de abril de 2010 en Sevilla, junto a otros tres artistas que participaron: María AA. Iván Tovar y Fernando Millán. En octubre de este mismo año, los comisarios del Festival Internacional de Arte Contemporáneo EC3. Encuentros'10, seleccionaron esta vídeoperformance ("Proceso de Paz") en Algeciras (Cádiz) en el mes de Octubre. Se editó un catálogo. Asumieron el coste de producción y me pagaron desplazamiento y alojamiento en un buen hotel de la ciudad para asistir a su inauguración. Nada que ver con la primera invitación fallida de Rinat.

Como remate a modo de guinda del "pastel", dos años después me invita un comisario internacional de arte contemporáneo Alexis Mendoza a participar en la III BIENAL DE ARTE LATINOAMERICANO. "Illusory Correlation" a participar con esta vídeo-performance en el Bronx Museum de New York. (USA). Esto demostró que una obra de arte, si tiene calidad, llega al sitio que se merece, aunque el inicio sea una negativa o una censura para su muestra. 
Revista de Estudios en Sociedad, Artes y Gestión Cultural
Monográfico Extraordinario III

Noviembre 2020

Ensayo

ISSN: 2340-9096

https://dx.doi.org/10.17561/rtc.extra3.5725

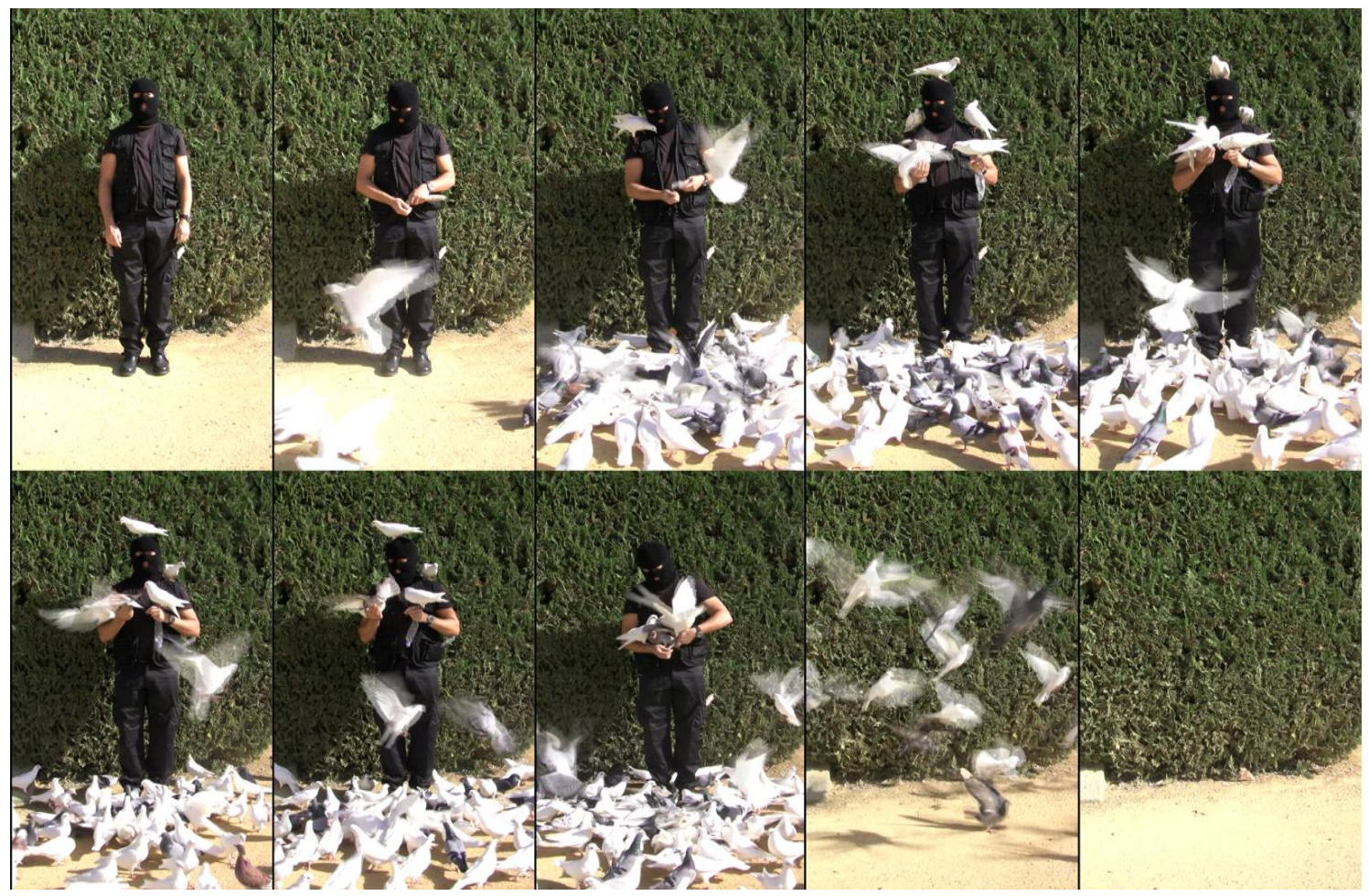

Fotogramas de la vídeo-performance "Proceso de paz: negociaciones multilaterales para un proceso sostenible de paz”. Autor: Jesús Algovi González Villegas. Fotografías del autor.

\section{Enlaces}

https://www.jesusalgovi.es/copia-de-the-river-of-memories

\section{https://www.jesusalgovi.es/CV}

https://vimeo.com/17806005 
